\title{
Thymoquinone reduces cardiac damage caused by hypercholesterolemia in apolipoprotein E-deficient mice
}

\author{
Jingyi Xu', Liyue Zhu², Hongyang Liư ${ }^{3}$, Mengye Li ${ }^{4}$, Yingshu Liu ${ }^{5}$, Fan Yang ${ }^{6}$ and Zuowei Pei ${ }^{6 *}$ (D
}

\begin{abstract}
Background: Hypercholesterolemia is a well-established risk factor for cardiac damage, which can lead to cardiovascular diseases. Many studies have shown that thymoquinone protected rats from doxorubicin-induced cardiotoxicity and cardiac damage. The aim of this study was to investigate the possible protective effects of thymoquinone against cardiac damage in apolipoprotein $\mathrm{E}$ knockout $\left(\mathrm{ApoE}^{--}\right)$mice.

Methods: Eight-week-old male ApoE ${ }^{-/-}$mice were randomly divided into three groups: control group fed a normal diet (ND group), a high cholesterol diet (HD group) or HD mixed with thymoquinone (HD + TQ group). All groups were fed the different diets for 8 weeks. Blood samples were obtained from the inferior vena cava and collected in serum tubes. The samples were then stored at $-80^{\circ} \mathrm{C}$ until used. Coronal sections of heart tissues were fixed in $10 \%$ formalin and then embedded in paraffin for histological evaluation. The remainder of the heart tissues was snap-frozen in liquid nitrogen for mRNA or immunohistochemical analysis.
\end{abstract}

Results: The metabolic characteristics of total cholesterol (TC), low-density lipoprotein-cholesterol (LDL-C), and high-sensitivity C-reactive protein (hs-CRP) were lower in $\mathrm{ApoE}^{-/-} \mathrm{HD}+\mathrm{TQ}$ mice than in $\mathrm{ApoE}^{-/-} \mathrm{HD}$ mice. Lectin-like oxidized low-density lipoprotein receptor-1 (LOX-1) gene and protein expression was lower in the heart tissue of $\mathrm{ApoE}^{-1-} \mathrm{HD}+\mathrm{TQ}$ mice than in those of $\mathrm{ApoE}^{-/-} \mathrm{HD}$ mice. Furthermore, the levels of macrophages and pro-inflammatory cytokines were lower in the cardiac tissues of $\mathrm{ApoE}^{-1-} \mathrm{HD}+\mathrm{TQ}$ mice than in those of $\mathrm{ApoE}^{-/-} \mathrm{HD}$ mice.

Conclusions: These results indicate that thymoquinone may provide a potential therapeutic target for cardiac damage caused by hypercholesterolemia.

\section{Background}

$\mathrm{ApoE}^{-1-}$ mice are considered a well-accepted model of hypercholesterolemia [1]. Hypercholesterolemia leads to the development of cardiovascular diseases (CVD). These comprise disorders of the heart and blood vessels that cause various fatal events $[2,3]$.

In $\mathrm{ApoE}^{-/-}$mice, hypercholesterolemia accelerates lipid deposition, atherosclerosis, and chronic inflammation [4, 5]. This process is enhanced in the presence of elevated levels of plasma lipids. Macrophages phagocytose oxidized lipids and form foam cells. Macrophage-derived foam cells release cytokines to recruit more macrophages to the lesions and

\footnotetext{
*Correspondence: pzw_dl@163.com

${ }^{6}$ Department of Cardiology, Affiliated Zhongshan Hospital of Dalian

University, No. 6 Jiefang Street, Dalian 116001, China

Full list of author information is available at the end of the article
}

influence lipid deposition [6]. However, the underlying pathophysiological mechanisms of the relationship between hypercholesterolemia and cardiac damage are not yet fully understood, especially in lipid deposition.

Recently, there has been a growing interest in using natural phytochemical compounds for alternative treatments of several conditions including cardiovascular diseases. Indeed, it has been estimated that at least $25 \%$ of the drugs used over the past few decades have been directly derived from plants and approximately $25 \%$ are chemically altered natural products [7]. Thymoquinone is one of these compounds. It is the main active ingredient of Nigella sativa, commonly known as black cumin or black seed, an annual flowering plant native to some areas such as the Mediterranean countries [8]. Since its first extraction in 1963 [9], thymoquinone has been shown to act as a potent free

(C) The Author(s). 2018 Open Access This article is distributed under the terms of the Creative Commons Attribution 4.0 International License (http://creativecommons.org/licenses/by/4.0/), which permits unrestricted use, distribution, and 
radical and superoxide scavenger [10-12]. In addition, it has been shown to have anti-inflammatory properties in in vivo and in vitro studies $[13,14]$. It has also been shown to act as lipid peroxidation inhibitor and superoxide radical scavenger in doxorubicin (DOX)-induced cardiotoxicity in rats [15]. The aim of this study was to determine the role of thymoquinone in hypercholesterolemia-induced cardiac damage. Our results contribute to the understanding of the beneficial role and action mechanism of thymoquinone in hypercholesterolemia-induced cardiac disorders.

\section{Methods}

\section{Animal studies}

All animal studies were approved by the Animal Studies Committee of the affiliated Zhongshan Hospital of Dalian University. ApoE ${ }^{-/-}$mice were purchased from Beijing Vital River Lab animal technology Co., LTD. (Beijing, China). All mice were maintained under constant conditions (temperature, $23-25^{\circ} \mathrm{C}$; humidity, $40-60 \%$; $12 \mathrm{~h}$ light/dark cycle). At 8 weeks of age, the male mice were randomly divided into the following three groups: $\mathrm{ApoE}^{-/-}$mice fed a normal diet which not contain cholesterol $(n=7)$, a high-cholesterol diet $(n=7)$ or thymoquinone $(25 \mathrm{mg} / \mathrm{kg} / \mathrm{d}$; Sigma-Aldrich, St. Louis, MO, USA) in combination with a high-cholesterol diet $(n=7)$. The high-cholesterol diet contained $1.5 \%$ cholesterol and $15 \%$ fat. The experimental diet was purchased from the Shanghai Slac Laboratory Animal Co., Ltd. (Shanghai, China). After 8 weeks different diet, blood samples were obtained from the inferior vena cava and collected in serum tubes. The samples were then stored at $-80{ }^{\circ} \mathrm{C}$ until used. Coronal sections of heart tissues were fixed in 10\% formalin and then embedded in paraffin for histological evaluation. The remainder of the heart tissues was snap-frozen in liquid nitrogen for mRNA or immunohistochemical analysis. All animal experiments were performed in accordance with the Guide for the Care and Use of Laboratory Animals. The study was approved by the ethical committee of the affiliated Zhongshan Hospital of Dalian University.

\section{Biochemical measurements}

Serum was obtained and stored at $-80{ }^{\circ} \mathrm{C}$. Total cholesterol, low-density lipoprotein cholesterol (LDL-c), and high-sensitivity C-reactive protein (hs-CRP) were measured using a Hitachi 7020 automatic analyzer (Hitachi, Tokyo, Japan).

\section{Haematoxylin and eosin staining (HE staining)}

Cardiac tissues were fixed in 10\% buffered formalin solution for $30 \mathrm{~min}$ and then dehydrated in 75\% ethanol overnight, followed by paraffin embedding. Serial sections $(4 \mu \mathrm{m})$ were subjected to haematoxylin and eosin (HE) staining for assessing the pathological changes.

\section{Periodic acid-Schiff staining}

Cardiac tissues from each group were stored in 10\% formalin, dehydrated in an ascending series of alcohol $(75,85,90$, and $100 \%$ alcohol, 5 min each) and then embedded in paraffin wax. The $4 \mu \mathrm{m}$-thick paraffin sections were sliced from these paraffin-embedded tissue blocks. Tissue sections were then de-paraffinized via immersion in xylene (3 times, 5 min each) and rehydrated using a descending series of alcohol (100, 90, 85, and 75\% alcohol, 5 min each). Biopsy samples were stained using Periodic Acid-Schiff (PAS) stain to investigate changes in cardiac morphology and fibrosis. Red staining represented lipid depositon.

\section{Immunohistochemistry analysis}

Immunohistochemistry was performed using the Histone Simple stain kits (Nichirei, Tokyo, Japan) according to the manufacturer's instructions. Briefly, paraffin-embedded sections were deparaffinized with xylene and then rehydrated in a descending series of ethanol concentrations. The sections were treated for 15 min with $3 \% \mathrm{H}_{2} \mathrm{O}_{2}$ in methanol to inactivate endogenous peroxidases and were then incubated at room temperature for $1 \mathrm{~h}$ with the primary antibodies against LOX-1 (rabbit anti-LOX-1 antibody, 1:200; Abcam, England) or CD68 (rabbit anti-CD68 antibody, 1:500; Abcam, England). All sections were analyzed using an Olympus $B \times 40$ upright light microscope (Olympus, Tokyo, Japan). For each staining, totally $3 \times 7$ sections ( 7 mice) per group were analyzed and the representative images were presented. All image analyses were done by a blinded reviewer.

\section{RNA isolation and quantitative real-time RT-PCR}

Total RNA was isolated from heart tissues using ISOGEN (Nippon gene, Tokyo, Japan) according to the manufacturer's protocol. Complementary DNA (cDNA) was synthesized from total RNA using a first-strand cDNA synthesis kit (SuperScript VILO cDNA Synthesis Kit; Life Technologies, Carlsbad, CA, USA) according to the manufacturer's instructions. Gene expression was quantitatively analyzed by real-time RT-PCR using fluorescent SYBR Green technology (Light Cycler; Roche Molecular Biochemicals). The cDNA amplification was performed as follows: the first cycle was maintained at $95{ }^{\circ} \mathrm{C}$ for $30 \mathrm{~s}$, followed by 38 cycles consisting of denaturation $\left(95^{\circ} \mathrm{C}\right.$ for $10 \mathrm{~s})$, annealing $\left(60{ }^{\circ} \mathrm{C}\right.$ for $\left.20 \mathrm{~s}\right)$, and extension $\left(72{ }^{\circ} \mathrm{C}\right.$ for 15 s). The LOX-1, SRA1,CD36, ABCA1,TNF- $\alpha$ and IL-6 were then processed using the $2-\Delta \Delta \mathrm{Ct}$ method, during which a single calibrated sample was compared against the gene expression of every unknown sample. The primer sequences are listed in Table 1.

\section{Western blotting of heart tissues}

Proteins were extracted from heart tissues using radioimmunoprecipitation assay buffer (P0013B; Beyotime, Shanghai, 
Table 1 Primer oligonucleotide sequences

\begin{tabular}{|c|c|}
\hline Gene & Primers \\
\hline \multirow[t]{2}{*}{ LOX-1 } & F:5'-CAAAGTCTCCCAACCAACCTGCAA-3' \\
\hline & R:5'-ACATCCTGTCTITCATGCGGCAAC-3' \\
\hline \multirow[t]{2}{*}{ SRA1 } & F:5'-GTTAAAGGTGATGGGGGACA-3 \\
\hline & R:5'-TCCCCTTCTCTCCCTTTTGT-3' \\
\hline \multirow[t]{2}{*}{ CD36 } & F:5'-CCTTAAAGGAATCCCCGTGT-3' \\
\hline & R:5'-TGCATTTGCCAATGTCTAGC-3' \\
\hline \multirow[t]{2}{*}{$A B C A 1$} & F:5'-AGCCAGAAGGGAGTGTCAGA-3' \\
\hline & R:5'-CATGCCATCTGGGTAAACCT-3' \\
\hline \multirow[t]{2}{*}{ TNF-a } & F:5'-TCTCATGCACCACCATCAAGGACT-3' \\
\hline & R:5'-ACCACTCTCCCTITGCAGAACTCA-3' \\
\hline \multirow[t]{2}{*}{ IL-6 } & F:5'-TACCAGTTGCCTTCTTGGGACTGA-3' \\
\hline & R:5'-TAAGCCTCCGACTTGTGAAGTGGT-3' \\
\hline \multirow[t]{2}{*}{$\beta$-actin } & F:5'-CGATGCCCTGAGGGTCTIT-3' \\
\hline & R:5'-TGGATGCCACAGGATTCCAT-3' \\
\hline
\end{tabular}

China). The samples were electrophoresed on $10 \%$ SDS-PAGE gels and proteins were transferred to polyvinylidene fluoride membranes (PVDF) (Immobilon, Millipore, Billerica, MA, USA). The membranes were blocked in Tris-buffered saline with $0.1 \%$ Tween-20 (TBS-T) containing 5\% skim milk, then incubated in primary antibody diluents (P0023A; Beyotime), and gently shaken overnight at $4{ }^{\circ} \mathrm{C}$. Primary antibodies against LOX-1 (rabbit anti-LOX-1 antibody, 1:250; Abcam), phospho-ERK (Rabbit anti-phospho-ERK, 1:1000; Cell Signalling Technology), and $\beta$-actin (1:1000; Cell Signalling Technology) were used. The membranes were then incubated with the secondary antibody (anti-rabbit Ig-G, 1:1000; Cell Signalling Technology) for $1 \mathrm{~h}$. This analysis was independently performed three times. The protein levels are expressed as protein/ $\beta$-actin ratios to minimize loading differences. The relative signal intensity was quantified using $\mathrm{NIH}$ Image J software.

\section{Statistical analysis}

All data were presented as the mean \pm SEM. Statistical analysis was performed using SPSS software version 23.0 (SPSS Inc., Chicago, IL, USA). Intergroup variation was measured using one-way ANOVA and subsequent Tukey's test. The minimal level for statistical significance was set at $P<0.05$.

\section{Results}

\section{Metabolic characterization}

The metabolic characteristics of $\mathrm{ApoE}^{-/-}$mice after 8 weeks of dietary treatment are summarized in Fig. 1. Heart/body weights did not differ among the three groups. The ApoE ${ }^{-/}$HD mice group showed markedly increased total cholesterol and low-density lipoprotein levels, but these significantly decreased in the HD + TQ group. There was no difference between the HD + TQ group and the control group. Hs-CRP levels significantly decreased in the HD + TQ group compared to that in the HD group.

\section{Thymoquinone reduced lipid deposition on histological assessments in heart structure of $\mathrm{ApoE}^{-/-}$mice fed HD} $\mathrm{HE}$ and PAS staining facilitated the visualization of cardiac tissular disorder, inflammatory cells infiltration and massive fibrosis with cardiac damage of hypercholesterolemia. Treatment with thymoquinone was helpful for ameliorating inflammatory cells infiltration and lipid deposition in $\mathrm{ApoE}^{-/-} \mathrm{HD}+\mathrm{TQ}$ group mice compared to $\mathrm{ApoE}^{-/-} \mathrm{HD}$ group mice (Fig. 2).

\section{Thymoquinone reduced LOX-1 gene expression in the heart tissue of $\mathrm{ApoE}^{-/-}$mice fed HD}

To investigate the mechanism of lipid accumulation in the heart, gene expression of relevant receptors and the TP-binding cassette transporter A1 (ABCA1) was examined by RT-PCR. LOX-1 gene expression significantly increased in the heart tissue of $\mathrm{ApoE}^{-/-} \mathrm{HD}$ group mice compared to that in control mice. The increased expression of LOX-1 was suppressed in the ApoE ${ }^{-/-} \mathrm{HD}+\mathrm{TQ}$ group. Expression of scavenger receptor-class A (SR-A) and CD36 increased in $\mathrm{ApoE}^{-1-} \mathrm{HD}$ mice compared to that in the control group. However, the levels were similar to those of $\mathrm{ApoE}^{-/-} \mathrm{HD}+\mathrm{TQ}$ mice. Expression of ABCA1 did not differ among the three groups (Fig. 3a). These results suggest that LOX-1, SR-A, and CD36 influence lipid accumulation in the heart tissue of ApoE ${ }^{-/} \mathrm{HD}$ mice. LOX-1, in particular, appears to be a critical factor for mitigation of lipid accumulation in the heart tissue of $\mathrm{ApoE}^{-/-} \mathrm{HD}+\mathrm{TQ}$ mice compared to that in $\mathrm{ApoE}^{-/-} \mathrm{HD}$ mice.

\section{Thymoquinone reduced tumor necrosis factor (TNF)- $a$} and interleukin (IL)- 6 gene expression in the heart tissue of $\mathrm{ApoE}^{-/-}$mice fed HD

To examine the involvement of pro-inflammatory cytokines in hypercholesteremic cardiac damage, IL- 6 and TNF- $\alpha$ gene expression was measured by real-time PCR. Both IL-6 and TNF- $\alpha$ were up-regulated in $\mathrm{ApoE}^{-/-} \mathrm{HD}$ mice. However, this up-regulation was attenuated in $\mathrm{ApoE}^{-/-} \mathrm{HD}+\mathrm{TQ}$ mice (Fig. 3b).

\section{Thymoquinone reduced LOX-1 expression in the hearts} tissue with immunohistochemistry

To evaluate LOX-1 expression in the heart tissue, LOX-1 immunostaining was performed (Fig. 4). The HD + TQ group mice showed a markedly reduced LOX-1 protein expression in the heart tissue compared to $\mathrm{ApoE}^{-/} \mathrm{HD}$ mice. These results indicate that thymoquinone reduced LOX-1 protein expression in $\mathrm{ApoE}^{-/-} \mathrm{HD}$ mice. 

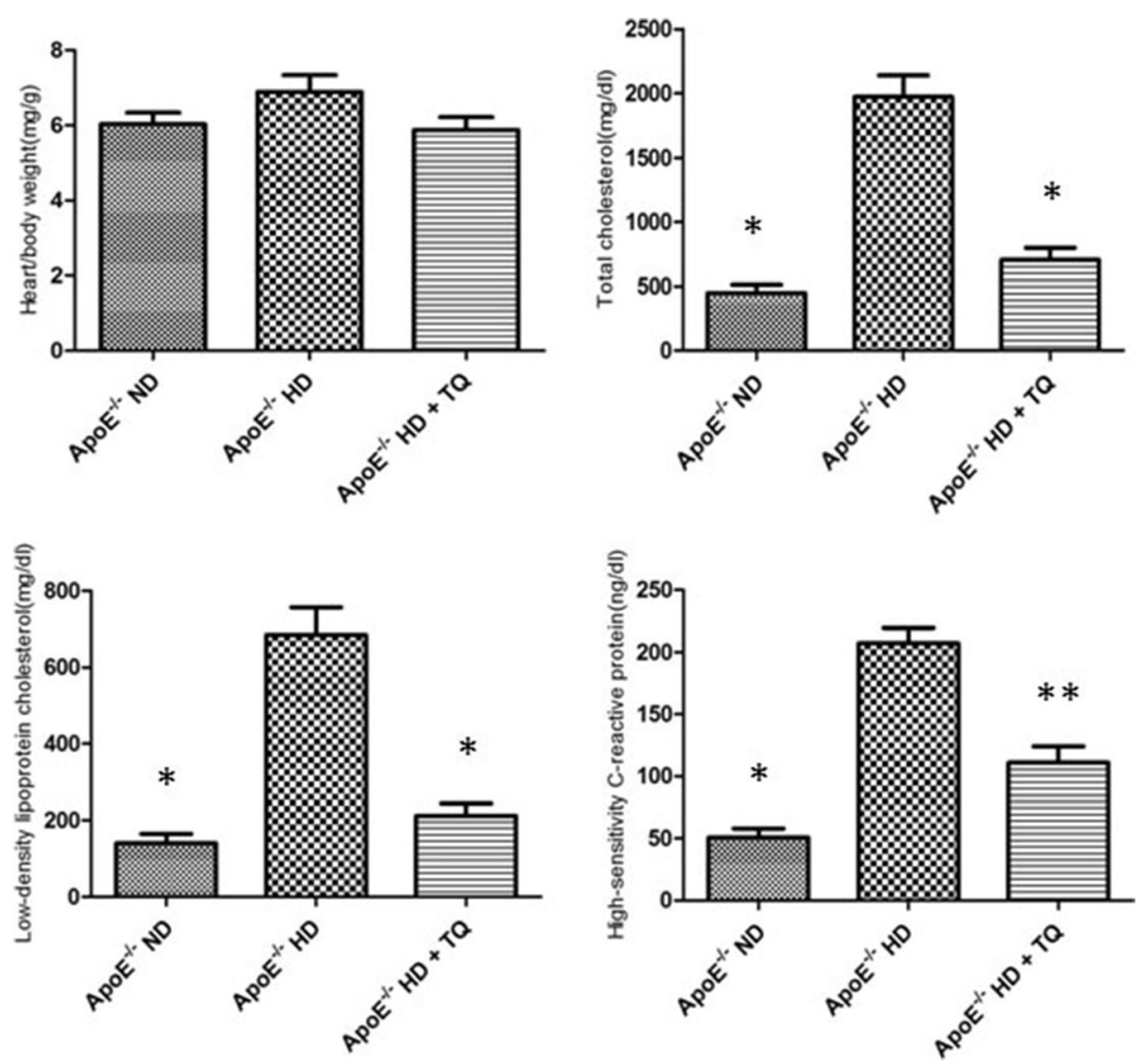

Fig. 1 Metabolic data from the three mice groups after 8 weeks of different diets. Heart/body weights, total cholesterol, low-density lipoprotein, and high-sensitivity C-reactive protein of three groups after 8 weeks of different treatments are presented here. Data are means \pm SEM; $n=6-7$ per group. ${ }^{*} P<0.01$ vs ApoE ${ }^{-/} \mathrm{HD}$; ${ }^{* *} P<0.05$ vs $\mathrm{ApoE}^{-/-} \mathrm{HD}$

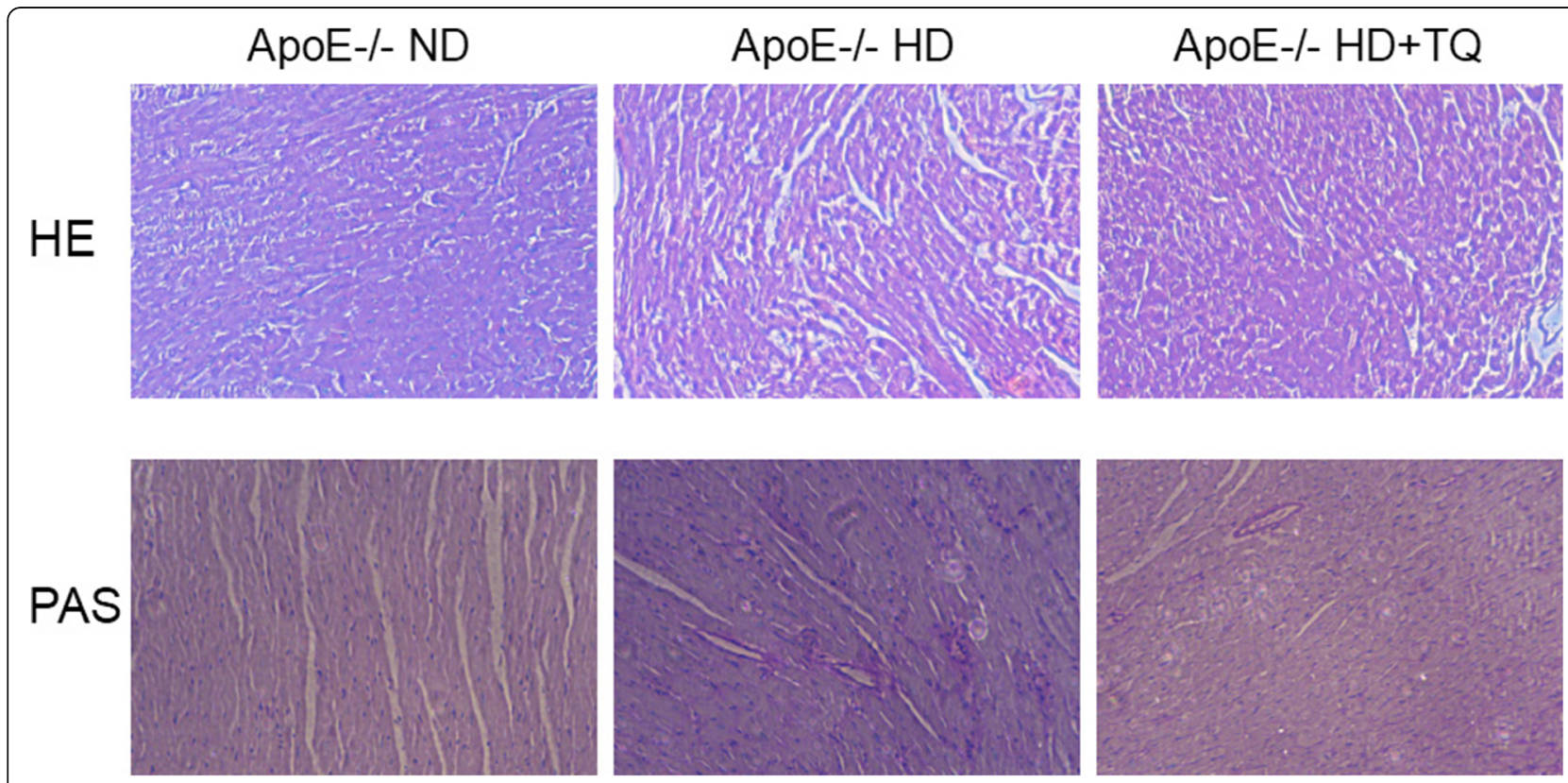

Fig. $2 \mathrm{HE}$ and PAS staining in heart tissues of three groups. Thymoquinone could ameliorate inflammatory cells infiltration and lipid deposition in $\mathrm{ApoE}^{-/-} \mathrm{HD}+\mathrm{TQ}$ group mice. Magnification $40 \mathrm{X}$ 


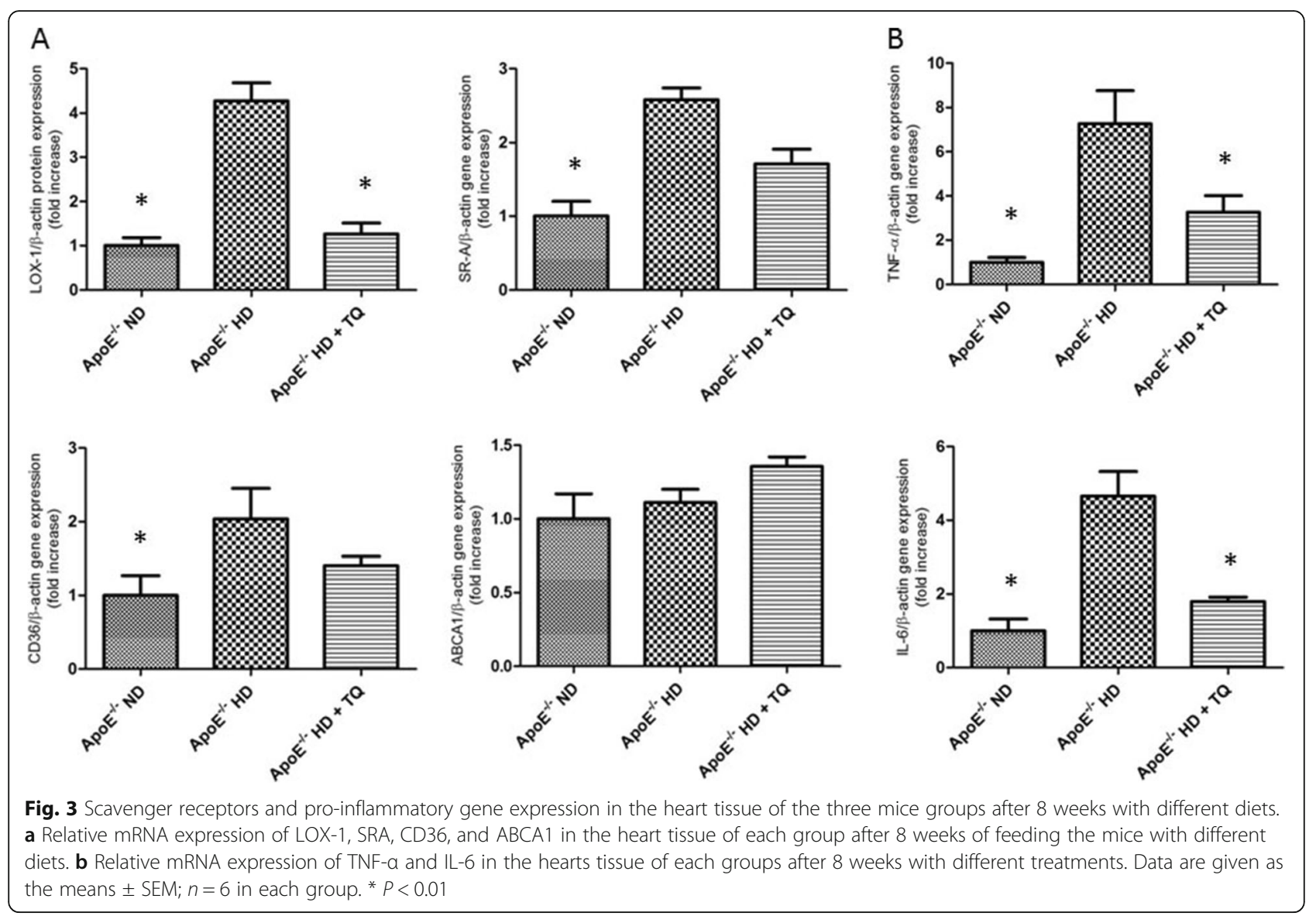

Thymoquinone reduced macrophages in the heart tissue of $\mathrm{ApoE}^{-/-}$mice in the HD group

To detect infiltrating macrophages, immunohistochemical analysis using CD68 was performed (Fig. 5). The mice in the HD + TQ group showed a markedly reduced CD68-positive staining in the heart compared to $\mathrm{ApoE}^{-/} \mathrm{HD}$ mice. These results indicate that thymoquinone reduced macrophage infiltration in the $\mathrm{ApoE}^{-/-} \mathrm{HD}$ mouse hearts.

Thymoquinone reduced LOX-1 protein expression in the hearts of $\mathrm{ApoE}^{-/-} \mathrm{HD}$ mice

To evaluate LOX-1 protein expression in the heart tissue, LOX-1 protein immunoblotting was performed (Fig. 6a).

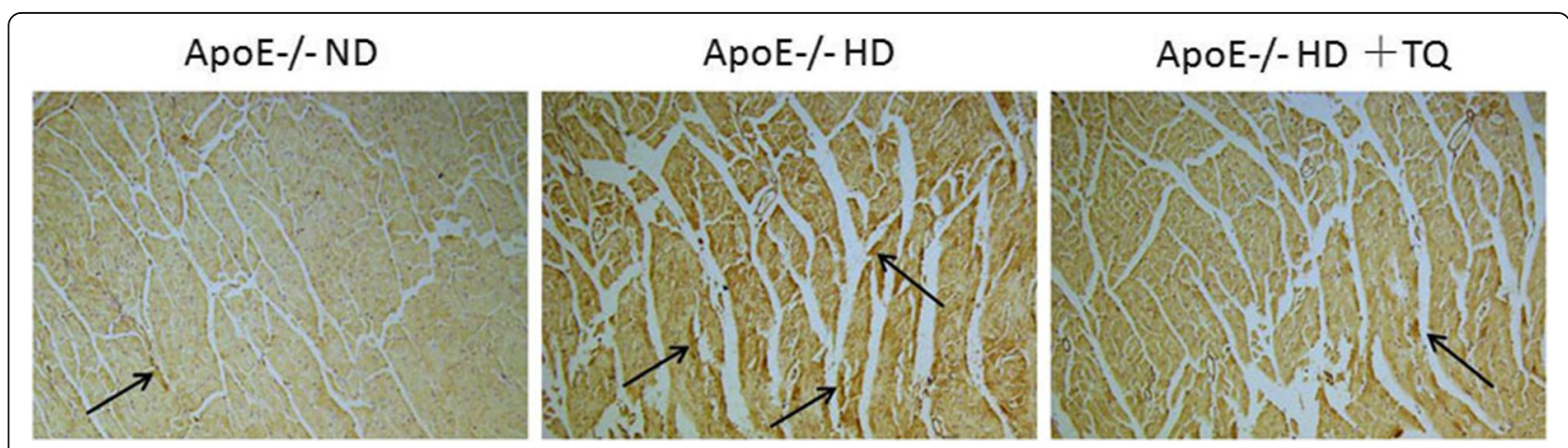

Fig. 4 LOX-1 expression in the heart tissue of the three groups after 8 weeks with different treatments. Representative immunohistochemistry staining for LOX-1 in heart tissue of mice fed with different diets. Magnification $40 \mathrm{X}$. Arrows indicate positively stained cells 


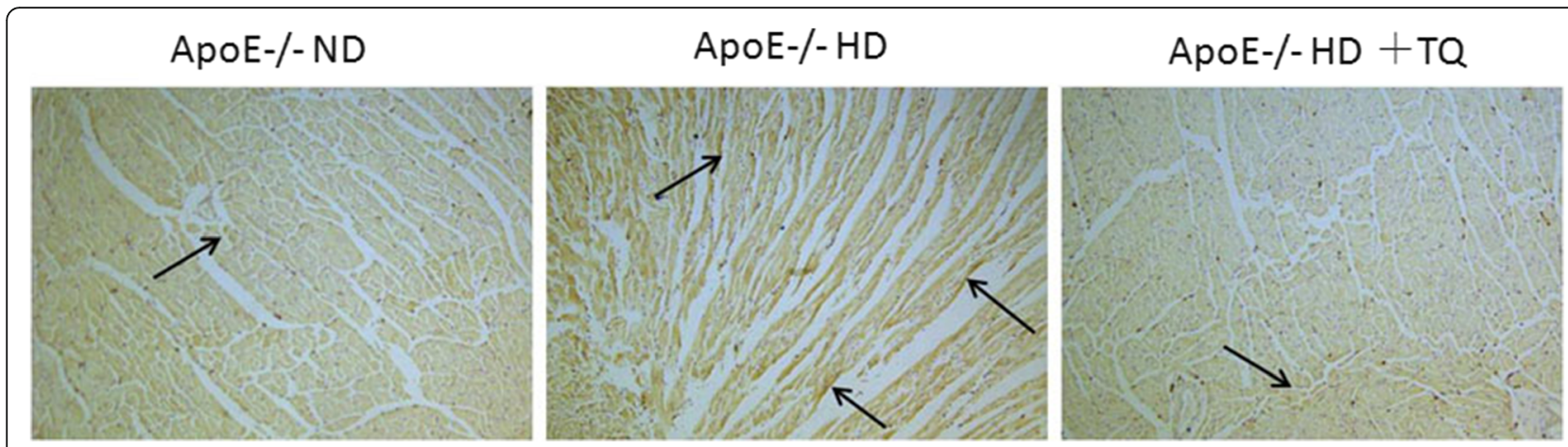

Fig. 5 CD68 expression in the hearts of the three groups after 8 weeks with different treatments. Representative immunohistochemistry staining for CD68 expression in heart. Magnification 40 X. Arrows indicate positively stained cells

We found that the LOX-1 protein levels in $\mathrm{ApoE}^{-/} \mathrm{HD}+$ TQ mice were significantly suppressed compared to that in the $\mathrm{ApoE}^{-/-} \mathrm{HD}$ group (Fig. 6b).

\section{Thymoquinone reduced phospho-ERK levels in the hearts tissue of $\mathrm{ApoE}^{-/-} \mathrm{HD}$ mice}

Protein kinases play a role in foam cell formation, lipid deposition, and phosphorylation of -ERK. To analyze the phosphorylation of ERK, protein immunoblotting was performed (Fig. 7a). We found that the phosphorylation level of ERK in $\mathrm{ApoE}^{-/-} \mathrm{HD}+\mathrm{TQ}$ mice was significantly suppressed compared to that in $\mathrm{ApoE}^{-/} \mathrm{HD}$ mice (Fig. 7b).

\section{Discussion}

This study demonstrates that thymoquinone has a protective effect on cardiac damage, which against progressive of lipid deposition, pro-inflammatory cytokine, and macrophage accumulation secretion elicited by hypercholesterolemia.
According to the metabolic characteristics, we found that TC and LDL-c increased in the HD mouse group compared with the ND group of $\mathrm{ApoE}^{-/-}$mice. These results are in agreement with the reports by Daniel Kolbus [16]. Interestingly, TC and LDL-c were significantly suppressed in the HD + TQ group compared to that in the HD group. Several clinical studies have indicated that the hs-CRP level reflects the instability of atherosclerotic lesions and it can be used as a biomarker for risk prediction of cardiovascular events [17-20]. Our results indicate that thymoquinone influences the cholesterol metabolism and hs-CRP. However, further studies are needed to clarify the mechanisms.

Hypercholesterolemia is a major independent risk factor of cardiac damage. Hyperlipidemia promotes lipid deposition and inflammation in the aorta $[21,22]$. In our study, we observed cardiac tissular disorder, inflammatory cells infiltration and massive fibrosis with cardiac damage of hypercholesterolemia by HE and PAS staining. There were less inflammatory cells infiltration and lipid deposition in

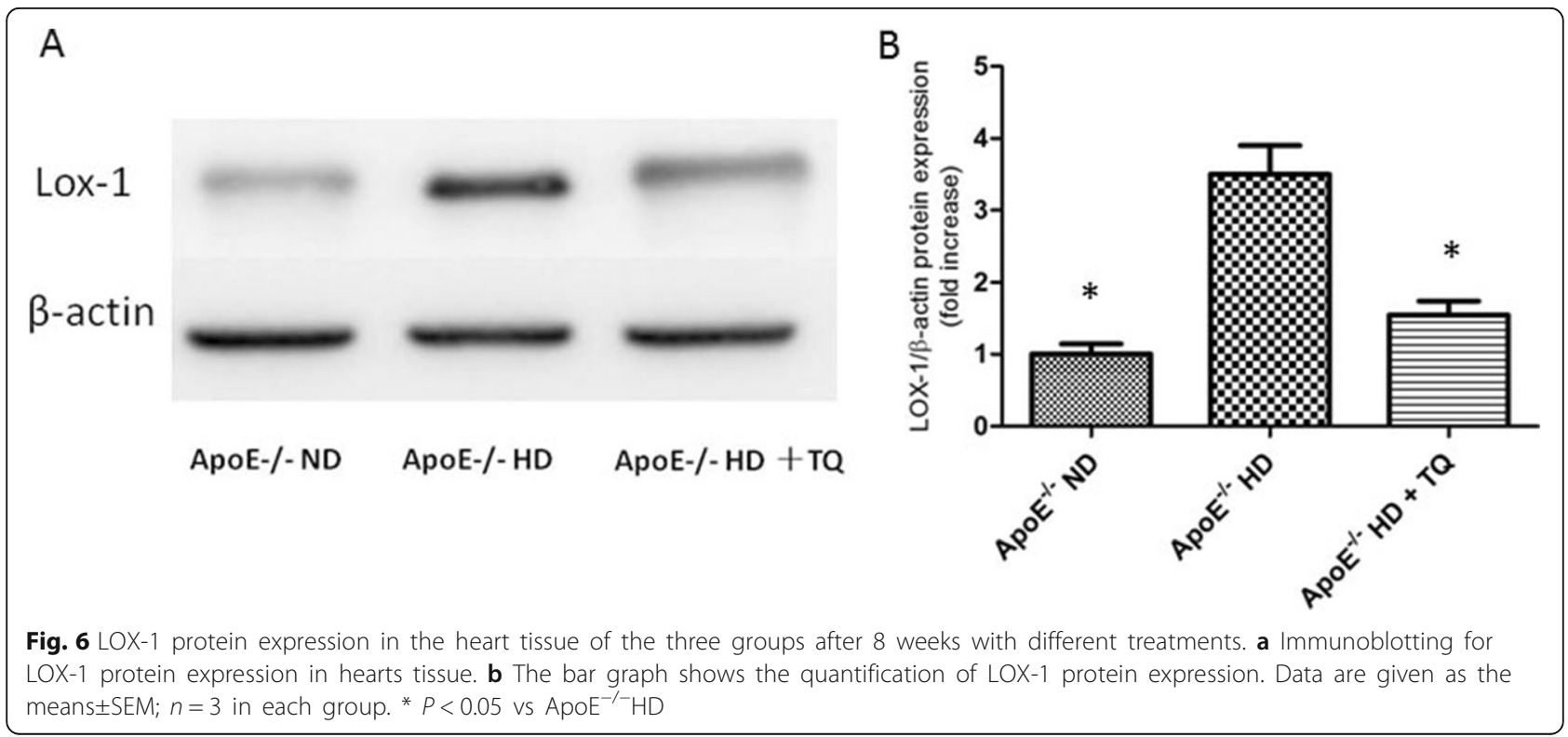



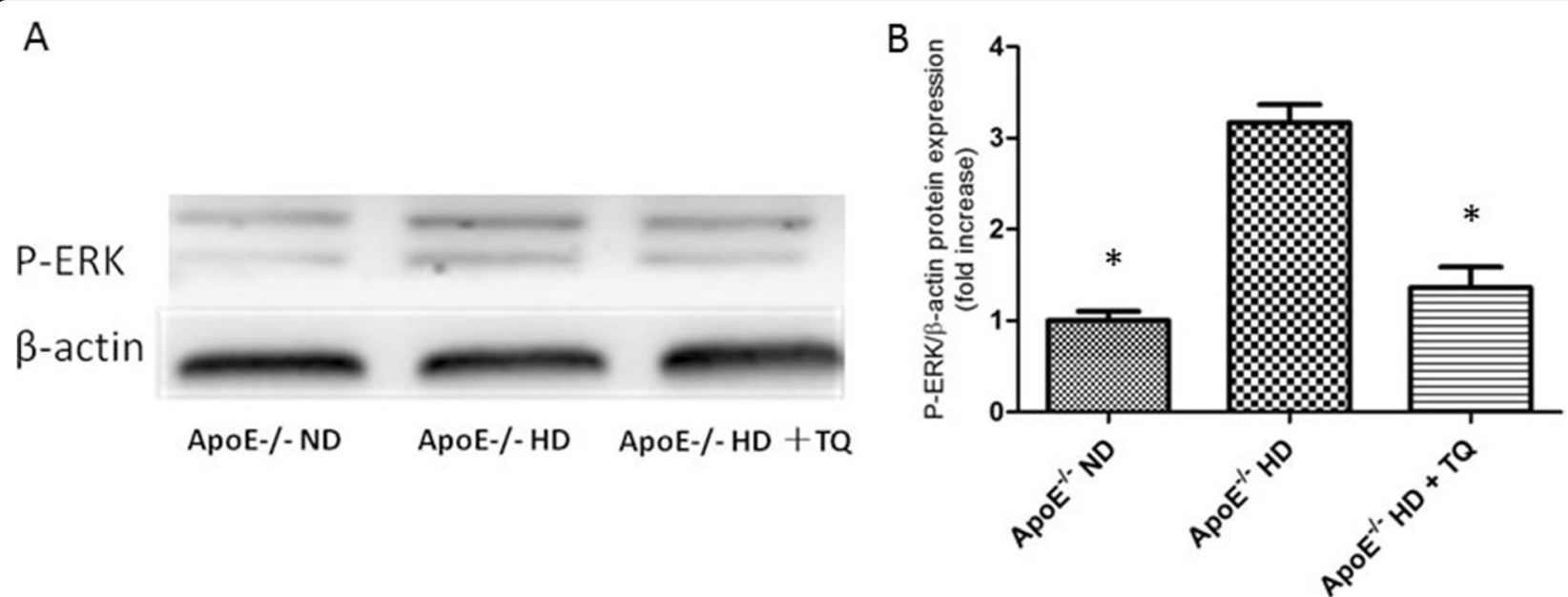

Fig. 7 Phosphor-ERK levels in the hearts of the three groups after 8 weeks with different treatments. a Immunoblotting for phosphor-ERK levels in heart tissues. $\mathbf{b}$ The bar graph shows the quantification of phosphor-ERK levels. Data are given as the means \pm SEM; $n=3$ in each group. * $P<0.05$ vs $\mathrm{ApoE}^{-/-} \mathrm{HD}$

$\mathrm{ApoE}^{-/-} \mathrm{HD}+\mathrm{TQ}$ group mice compared to $\mathrm{ApoE}^{-/-} \mathrm{HD}$ group mice. Cellular lipid homeostasis involves regulation of the influx, synthesis, catabolism, and efflux of lipids. An imbalance of these processes can result in the conversion of macrophages and vascular smooth muscle cells into foam cells. This process is mediated by several independent pathways, including SR-A, class B (CD36), and LOX-1 [23-25]. Pro-inflammatory genes (TNF- $\alpha$ and IL-6) were reported to be expressed at high levels and to contribute to cardiovascular diseases caused by hyperlipidemia [26, 27].

\section{Mechanism of action of thymoquinone}

Thymoquinone is a potent phytochemical anti-oxidant due to its scavenging activity against several ROS including superoxide anions, hydroxyl radicals, and singlet molecular oxygen, thus it can antagonize the adverse effects resulting from elevated ROS levels in various disorders $[15,28]$. It has been shown that thymoquinone and tert-butylhydroquinone (TBHQ), a structurally related synthetic compound, can robustly inhibit iron-dependent microsomal lipid peroxidation. The anti-oxidative potential of thymoquinone may be related to the redox properties of its quinone moiety and its unrestricted ability to cross physiological barriers and access subcellular compartments, all of which help its radical scavenging effects $[29,30]$.

These effects include the reduction of total blood cholesterol and lipid peroxidation levels during cardiac damage $[21,22,27]$. In a previous study, thymoquinone acted as an inhibitor of lipid peroxidation and superoxide radical scavenger in DOX-induced cardiotoxicity in rats. Moreover, thymoquinone protected against cypermethrin-induced necrosis, degeneration, and loss of striation in the heart. It resulted in a reversal of cypermethrin-induced oxidative stress and lipid peroxidation [15, 31].

\section{Thymoquinone affects gene expression}

In our study, we analyzed the gene expression of scavenger receptors including SR-A, CD36, and LOX-1. We found that LOX-1 gene expression was suppressed in the HD + TQ group of mice. LOX-1 was originally identified in endothelial cells. It is a $50-\mathrm{kDa}$ type II membrane glycoprotein that contains a short $\mathrm{N}$-terminal cytoplasmic domain, a single transmembrane domain, a short neck or stalk region, and an ox-LDL-binding C-terminal extracellular C-type lectin-like domain. On the cell surface, LOX-1 consists of 3 homodimers that are bound to ox-LDL, and it plays an important role in ox-LDL uptake and foam cell formation [32, 33]. In contrast, deletion of LOX-1 has been shown to reduce the uptake of oxidized LDL and inhibit atherosclerosis in mice fed a high-cholesterol diet [34]. Therefore, suppression of LOX-1 expression in $\mathrm{ApoE}^{-/-} \mathrm{HD}+\mathrm{TQ}$ mice may reduce foam cell formation. Thymoquinone also reduced LOX-1 protein expression in kidney tissues of $\mathrm{ApoE}^{-/-} \mathrm{HD}$ mice. Protein kinases regulate foam cell formation and lipid deposition. As shown earlier, enhanced LOX-1 expression was attenuated by inhibitors of ERK, PKC, and NF- $\mathrm{KB}$, indicating that the increased production of intracellular ROS and activation of the PKC/MAPK pathway are the initial signaling events in LOX-1 gene regulation [35]. Our results show that phosphorylation of ERK was significantly reduced in the $\mathrm{HD}+\mathrm{TQ}$ group compared to that in the HD group. We speculated that thymoquinone regulates LOX-1 via the phospho-ERK pathway.

\section{The role of thymoquinone in inflammation}

Pro-inflammatory genes (TNF- $\alpha$ and IL-6) have been reported to be expressed at high levels and contribute to 
kidney injury in hyperlipidemia [27, 36]. Furthermore, TNF- $\alpha$ and IL- 6 were shown to induce LOX-1 up-regulation in smooth muscle cells [37]. The present study shows that TNF- $\alpha$ and IL-6 gene expressions were reduced in the $\mathrm{HD}+\mathrm{TQ}$ group compared to the HD group. Attenuation of TNF- $\alpha$ and IL- 6 expression may have also reduced LOX-1 expression in ApoE ${ }^{-/} \mathrm{HD}+\mathrm{TQ}$ mice. It has been reported that thymoquinone reduces TNF- $\alpha$ and IL- 6 in blood and arthritis tissues. In addition, it protects tissues by reducing inflammation $[13,14]$.

Cardiac damage induced by hyperlipidemia is usually associated with an increase in the number of macrophages. Macrophage-derived foam cells release cytokines that recruit more macrophages to lesions and influence lipid deposition [6]. The marker CD68 identifies macrophages. CD68-positive cells were found in liver tissue damaged by hyperlipidemia [38]. In the present study, immunohistochemical staining with anti-CD68 antibody showed that CD68-positive cells significantly increased in the HD group compared to that in the ND group of $\mathrm{ApoE}^{-/-}$mice. However, mice in the HD + TQ group showed markedly reduced accumulation of CD68-positive cells in the heart tissue compared to mice of the HD group. This indicates that thymoquinone reduces macrophage accumulation in mice of the HD group.

\section{Conclusions}

Our study establish that thymoquinone contributes to the mitigation of hypercholesterolemic cardiac damage as shown by the downregulation of LOX-1 and the suppression of foam cell formation, lipid deposition, and macrophage accumulation. These findings provide new insights for the role of thymoquinone in hypercholesterolemia-induced cardiac damage and raise the possibility of a novel therapeutic intervention for the treatment of the progression of cardiovascular diseases.

\section{Abbreviations \\ ABCA1: ATP-binding cassette transporter A1; Hs-CRP: high-sensitivity C-reactive protein; IL-6: interleukin- 6; LDL-c: low-density lipoprotein cholesterol; LOX- 1: lectin-like oxidized low-density lipoprotein receptor-1; SRA: scavenger receptor-A; TC: total cholesterol; TNF-a: tumor necrosis factor-a}

\section{Funding}

The study was supported by grants from the The social development project of public welfare technology (No.2015C33121).

\section{Availability of data and materials}

The datasets used and analysed during the current study available from the corresponding author on reasonable request.

\section{Authors' contributions}

ZP designed this study; JX helped in performing experiments; LZ and YL analyzed data and interpreted the results of experiments; ML and FY prepared figures; ZP drafted the manuscript; JX and HL helped to revising of manuscript. All authors read and approved the final manuscript.

\section{Ethics approval and consent to participate}

This study was approved by the ethics committee of the affiliated Zhongshan Hospital of Dalian University. Written consent was obtained from all participants.

\section{Consent for publication}

Not applicable.

\section{Competing interests}

The authors declare that they have no competing interests.

\section{Publisher's Note}

Springer Nature remains neutral with regard to jurisdictional claims in published maps and institutional affiliations.

\section{Author details}

${ }^{1}$ Department of Endocrinology, Affiliated Zhongshan Hospital of Dalian University, No. 6 Jiefang Street, Dalian, China. ${ }^{2}$ Rehabilitation Center, Zhejiang Hospital, No. 12 Lingyin Road, Hangzhou, Zhejiang, China. ${ }^{3}$ Department of Heart Intensive Care Unit, the First Affiliated Hospital of Dalian Medical University, No.193 Lianhe Road, Dalian, China. ${ }^{4}$ Department of Special Medical Unit, the First Affiliated Hospital of Dalian Medical University, No. 193 Lianhe Road, Dalian, China. ${ }^{5}$ Department of Endocrinology Dalian Municipal Central Hospital, No. 42 Xuegong Road, Dalian, China. ${ }^{6}$ Department of Cardiology, Affiliated Zhongshan Hospital of Dalian University, No. 6 Jiefang Street, Dalian 116001, China.

Received: 2 September 2017 Accepted: 18 July 2018

Published online: 26 July 2018

\section{References}

1. Piedrahita JA, Zhang SH, Hagaman JR, Oliver PM, Maeda N. Generation of mice carrying a mutant apolipoprotein E gene inactivated by gene targeting in embryonic stem cells. Proc Natl Acad Sci U S A. 1992;10:4471-5.

2. Stone NJ, Robinson JG, Lichtenstein AH. American College of Cardiology American Heart Association Task Force on practice guidelines. Circulation. 2014;25:1-45.

3. Arsenault BJ, Kritikou EA, Tardif JC. Regression of atherosclerosis. Curr Cardiol Rep. 2012;4:443-9.

4. Karshovska E, Zhao Z, Blanchet X. Hyperreactivity of junctional adhesion molecule A-deficient platelets accelerates atherosclerosis in hyperlipidemic mice. Circ Res. 2015:4:587-9.

5. Zouwei P, Takafumi O, Tomoaki N. Osteopontin deficiency reduces kidney damage from hypercholesterolemia in apolipoprotein E-deficient mice. Sci Rep. 2016;10:1038.

6. De Winther MP, Hofker MH. Scavenging new insights into atherogenesis. J Clin Invest. 2000;8:1039-41.

7. Vuorelaa $P$, Leinonenb M, Saikkuc $P$. Natural products in the process of finding new drug candidates. Curr Med Chem. 2004;11:1375-89.

8. Gali-Muhtasib H, Roessner A, Schneider-Stock R. Thymoquinone: a promising anti-cancer drug from natural sources. Int J Biochem Cell Biol. 2006:8:1249-53.

9. El-Dakhakhny M. Studies on the chemical constitution of Egyptian N. Sativa L. seeds. Planta Med. 1963;11:465-70.

10. Awad AS, Kamel R, Sherief MA. Effect of thymoquinone on hepatorenal dysfunction and alteration of CYP3A1 and spermidine/spermine N-1-acetyltransferase gene expression induced by renal ischaemia-reperfusion in rats. J Pharm Pharmacol. 2011:8:1037-42.

11. Farag MM, Ahmed GO, Shehata RR, Kazem AH. Thymoquinone improves the kidney and liver changes induced by chronic cyclosporine a treatment and acute renal ischaemia/reperfusion in rats. J Pharm Pharmacol. 2015;5:731-9.

12. Mansour MA, Nagi MN, El-Khatib AS, Al-Bekairi AM. Effects of thymoquinone on antioxidant enzyme activities, lipid peroxidation and DT-diaphorase in different tissues of mice: a possible mechanism of action. Cell Biochem Funct. 2002;2:143-51.

13. Tekeoglu I, Dogan A, Demiralp LI. Effects of thymoquinone (volatile oil of black cumin) on rheumatoid arthritis in rat models. Phytother Res. 2006;10:869-71. 
14. Vaillancourt F, Silva P, Shi Q, Fahmi H, Fernandes JC, Benderdour M. Elucidation of molecular mechanisms underlying the protective effects of thymoquinone against rheumatoid arthritis. J Cell Biochem. 2011;1:107-17.

15. Nagi MN, Mansour MA. Protective effect of thymoquinone against doxorubicin-induced cardiotoxicity in rats: a possible mechanism of protection. Pharmacol Res. 2000;3:283-9.

16. Kolbus D, Ramos OH, Berg KE. CD8+ T cell activation predominate early immune responses to hypercholesterolemia in $\mathrm{Apoe}^{-} /^{-}$mice. BMC Immunol. 2010;10:1186.

17. Ridker PM, Hennekens $\mathrm{CH}$, Buring JE, Rifai N. C-reactive protein and other markers of inflammation in the prediction of cardiovascular disease in women. N Engl J Med. 2000;12:836-43.

18. Ridker PM, Cushman M, Stampfer MJ, Tracy RP, Hennekens CH. Inflammation, aspirin, and the risk of cardiovascular disease in apparently healthy men. N Engl J Med. 1997:14:973-9.

19. Matsushita K, Yatsuya $\mathrm{H}$, Tamakoshi K. High-sensitivity C-reactive protein is quite low in Japanese men at high coronary risk. Circ J. 2007;6:820-5.

20. Shimada K, Fujita M, Tanaka A. Elevated serum C-reactive protein levels predict cardiovascular events in the Japanese coronary artery disease (JCAD) study. Circ J. 2009;1:78-85.

21. Braun A, Zhang S, Miettinen HE. Probucol prevents early coronary heart disease and death in the high-density lipoprotein receptor SRBl/apolipoprotein E double knockout mouse. Proc Natl Acad Sci U S A. 2003;12:7283-8.

22. Guo X, Yamada S, Tanimoto A. Overexpression of peroxiredoxin 4 attenuates atheroscleros is in apolipoprotein E knockout mice. Antioxid Redox Signal. 2012;10:1362-75.

23. Abrass CK. Cellular lipid metabolism and the role of lipids in progressive renal disease. Am J Nephrol. 2004;1:46-53.

24. Glass CK, Witztum JL. Atherosclerosis: the road ahead. Cell. 2006:4:503-16.

25. Vaughan AM, Tang C, Oram JF. ABCA1 mutants reveal an interdependency between lipid export function, apoA-I binding activity, and Janus kinase 2 activation. J Lipid Res. 2009;2:285-92.

26. Tao Y, Xiong Y, Wang H. APOC3 induces endothelial dysfunction through TNF-a and JAM-1. Lipids Health Dis. 2016;10:1186.

27. Li W, Fang Q, Zhong P. EGFR inhibition blocks palmitic acid-induced inflammation in cardiomyocytes and prevents hyperlipidemia-induced cardiac injury in mice. Sci Rep. 2016;10:1038.

28. Mansour MA, Nagi MN, El-Khatib AS, Al-Bekairi AM. Effects of thymoquinone on antioxidant enzyme activities, lipid peroxidation and DTdiaphorase in different tissues of mice: a possible mechanism of action. Cell Biochem Funct. 2002;2:143-51.

29. Badary OA, Taha RA, Gamal El-Din AM, Abdel-Wahab MH. Thymoquinoneis a potent superoxide anion scavenger. Drug Chem Toxicol. 2003;2:87-98.

30. Daba MH, Abdel-Rahman MS. Hepatoprotective activity of thymoquinonein isolated rat hepatocytes. Toxicol Lett. 1998;1:23-9.

31. Ince S, Kucukkurt I, Huseyin Demirel H, Turkmen R, Sever E. Thymoquinone attenuates cypermethrin induced oxidative stress in Swiss albino mice. Pestic Biochem Phys. 2012;9:229-35.

32. Sawamura T, Kume N, Aoyama T, Moriwaki H, Hoshikawa H. An endothelial receptor for oxidized low-density lipoprotein. Nature. 1997;4:73-7.

33. Gao S, Geng YJ. LOX-1: a male hormone-regulated scavenger receptor for atherosclerosis. Vasc Pharmacol. 2013;5:138-43.

34. Hu C, Dandapat A, Sun L. LOX-1 deletion decreases collagen accumulation in atherosclerotic plaque in low-density lipoprotein receptor knockout mice fed a high-cholesterol diet. Cardiovasc Res. 2008;2:287-93.

35. Li L, Sawamura T, Renier G. Glucose enhances human macrophage LOX-1 expression: role for LOX-1 in glucose-induced macrophage foam cell formation. Circ Res. 2004:78992-901.

36. Mathias D, Mitchel RE, Barclay M. Low-dose irradiation affects expression of inflammatory markers in the heart of $\mathrm{ApoE}^{-1-}$ mice. PLoS One. 2015;3:1371.

37. Hofnagel O, Luechtenborg B, Stolle K. Proinflammatory cytokines regulate LOX-1 expression in vascular smooth muscle cells. Arterioscler Thromb VascBiol. 2004;10:1789-95.

38. Rudel $L L$, Lee $R G$, Parini P. ACAT2 is a target for treatment of coronary heart disease associated with hypercholesterolemia. Arterioscler Thromb Vasc Biol. 2005;6:112-1118.

\section{Ready to submit your research? Choose BMC and benefit from:}

- fast, convenient online submission

- thorough peer review by experienced researchers in your field

- rapid publication on acceptance

- support for research data, including large and complex data types

- gold Open Access which fosters wider collaboration and increased citations

- maximum visibility for your research: over $100 \mathrm{M}$ website views per year

At $\mathrm{BMC}$, research is always in progress.

Learn more biomedcentral.com/submissions 